\title{
Representações da Infância nos Discursos Pedagógicos: mutações e temporalidades
}

Crislei de Oliveira Custódio'

'Universidade de São Paulo (USP), São Paulo/SP - Brasil

RESUMO - Representações da Infância nos Discursos Pedagógicos: mutações e temporalidades. Este estudo analisa as representações da infância nos discursos pedagógicos com o objetivo de detectar mutações que ocorreram na imagem da criança-aluno na modernidade. Tem-se como principal hipótese que as diferentes imagens da infância forjadas no âmbito da Pedagogia estão intrinsecamente ligadas às transformações no relacionamento das sociedades modernas com a temporalidade.

Palavras-chave: Infância. Representação. Discurso Pedagógico. Regimes de Historicidade.

\begin{abstract}
Representations of Childhood in Pedagogical Discourses: mutations and temporalities. The present study analyzes representations of childhood in pedagogical discourses with the purpose of detecting mutations that occurred in the child-student image in modernity. The main hypothesis of this article assumes that the different images of childhood forged under Pedagogy are intrinsically linked to changes in the relationship of modern societies with temporality.

Keywords: Childhood. Representation. Pedagogical Discourse. Regimes of Historicity.
\end{abstract}

Educação \& Realidade, Porto Alegre, v. 42, n. 1, p. 299-321, jan./mar. 2017. 299 http://dx.doi.org/10.1590/2175-623654662 
Representações da Infância nos Discursos Pedagógicos

\section{Introdução}

A compreensão da infância como um período da vida dotado de especificidades é uma invenção moderna. Para alguns autores, uma das invenções mais humanitárias da modernidade, pois diz respeito a uma preocupação diferenciada em relação à educação e aos cuidados com as crianças. Embora não se possa afirmar que a Idade Média desconhecia qualquer sentimento de infância ou que pouco se ocupava de suas crianças, é fato que a modernidade inaugura um novo modo de se relacionar com os mais novos.

De sua aurora, entre o Humanismo e o Renascimento, até o nosso tempo, a imagem da infância moderna “[...] sofreu uma complexa evolução-transformação desenhando uma parábola, ou seja, um primeiro itinerário de crescimento, expansão e, logo, de declive-transformação que está se cumprindo sob nossos olhos"1 (Trisciuzzi; Cambi, 1993, p. 12). Nesse sentido, a infância moderna descrita por Ariès (1981) passou por mudanças em sua significação social e na relação que os adultos estabelecem com ela, tanto no contexto familiar quanto no âmbito da educação e da pedagogia.

$\mathrm{Na}$ esteira das mutações da representação ${ }^{2}$ da infância nos discursos pedagógicos, o que se pode notar é que, da época moderna à atualidade, a "[...] pedagogia se [coloca] como meta a tentativa de demarcar tanto os limites entre a infância e a idade adulta como os deveres e direitos que dizem respeito a cada um desses setores em que agora a população fica dividida" (Narodowski, 2001, p. 52). Nesse contexto, a definição do que é a infância, sua duração e sentido passam também pelo discurso teórico da pedagogia, o qual sofre rupturas e transformações nas imagens de infância que produz e ressignifica.

Entendida como um campo que se caracteriza por um conjunto de discursos fortemente prescritivos e normativos que objetivam estabelecer um outro pedagogizável - o qual precisa ser conduzido de sua condição atual a outro patamar -, a pedagogia é também o campo discursivo do qual emanam as orientações para a condução desse outro e no qual são definidas as capacidades e saberes necessários àquele que será o condutor ao longo do processo de formação. É nesse sentido que a pedagogia é compreendida aqui, sobretudo, como um conjunto de discursos que, ainda que assumam traços descritivos da realidade escolar e do aluno, versam sobre como deve ser a educação, como se deve ensinar, como deve agir o professor, como deve ser a escola, como o aluno deve aprender, dentre outras prescrições. Assim, seja na forma didática ou teórica, os discursos pedagógicos são, em geral, discursos que objetivam preceituar os modos de condução da criança no decorrer de sua educação.

Para analisar as mudanças nas representações da infância forjadas no âmbito da pedagogia, são propostas três categorias: infância-quarentena, infância singularizada e infância ensimesmada. Tais categorias visam exprimir três diferentes imagens da infância que podem ser encontradas nos discursos pedagógicos. A construção dessas 
categorias se baseou em cânones do campo, como as obras de Émile Durkheim, Maria Montessori, Édouard Claparède, John Dewey, Alain, Célestin Freinet, Alexander Neil, bem como em obras mais contemporâneas, como as de Georges Snyders, de Loris Malaguzzi e dos pedagogos de Reggio Emilia, e artigos acadêmicos atuais, ligados às perspectivas da pedagogia da infância e da sociologia da infância.

Embora os discursos que alicerçam as categorias analíticas e lhes servem de fontes sejam de épocas diferentes, não se pretende investigar essas representações de maneira cronológica e uniforme, visto que, na medida em que são ideias, não é possível tratá-las linearmente, como uma sucessão de noções que surgiram, entraram em decadência e foram suplantadas por outras. É óbvio que diferentes imagens coexistiram e coexistem no campo da pedagogia, disputaram e disputam a adesão de educadores ao mesmo tempo; no entanto, não há como negar também que, em momentos distintos, uma noção prevalece em detrimento da outra. Assim, este artigo visa analisar as representações da infância a partir das categorias enunciadas, examinando mais profundamente a noção que se destaca nos discursos contemporâneos, isto é, aqueles que datam dos últimos decênios do século XX até a atualidade.

Tem-se como hipótese que as transformações e rupturas da representação da infância nos discursos pedagógicos possuem uma estreita ligação com o modo como as sociedades modernas se relacionam com a temporalidade. Nesse sentido, crê-se que a compreensão pedagógica de uma infância cada vez mais centrada em si tem a ver com a ascensão e declínio da ideia de progresso e com a eleição do presente como tempo que ordena nossas relações com o mundo e com as novas gerações.

\section{Infância e suas Diferentes Representações nos Discursos Pedagógicos}

Entende-se por infância-quarentena a representação da criança como o não adulto, como um ser que deve ser separado e formado com vistas ao ideal de homem autônomo, civilizado e racional. A infância, nesta abordagem, assume-se como o degrau anterior à plenitude da vida adulta, como o estágio de formação do futuro homem e, portanto, como o lócus da falta e o período da vida de maior maleabilidade. A educação destinar-se-ia, pois, a formar o espírito da criança de modo a guiá-la em direção à sua maioridade.

Embora ainda presente, esta imagem se liga fundamentalmente à concepção moderna de infância, aquela que, de acordo com autores como Ariès (1981) e Postman (1999), a Idade Média não conhecera, já que entregava a educação das crianças à vida comunitária, não as submetendo a um processo de segregação e individualização. Tal noção social de infância se constituiu face à interposição de marcas distintas entre adultos e crianças.

Segundo Postman (1999), conforme se erigiu um novo ideal de adulto letrado, capaz de controlar suas pulsões naturais, individualista,

Educação \& Realidade, Porto Alegre, v. 42, n. 1, p. 299-321, jan./mar. 2017. 
Representações da Infância nos Discursos Pedagógicos

devoto da leitura laicizada e da autoridade da palavra impressa, tornouse fundamental a separação das crianças e consequente estabelecimento de uma classe de pessoas distinta. Esse grupo segregado deveria, na perspectiva moderna, ser preparado para a vida adulta.

No contexto da consolidação da cultura letrada, do advento da ciência moderna, da profusão dos valores e do modo de vida burgueses e face ao desenvolvimento econômico, os discursos pedagógicos se voltaram a pensar sobre o tipo de formação que a criança - agora segregada e tomada como indivíduo - deveria ter para atingir a esse ideal de homem. Dessa maneira, ao passo que a infância é pensada em relação a um adulto futuro, a criança é concebida, no interior de determinados escritos pedagógicos, como algo inacabado, em estado de vir a ser.

A coroação do indivíduo adulto é selada pelo Iluminismo e sua promessa de emancipação ética e política por meio do exercício pleno da razão e da autonomia. Para a tradição do pensamento filosófico, a idade da razão opunha-se à idade da des-razão - a infância -, a qual estaria sujeita ao domínio e aos mandamentos externos. Nesta concepção, portanto, a infância assume um estatuto paradoxal: “[...] território perigoso das paixões, do pecado e do erro, zona escura sem os caminhos que traçam as palavras e que ilumina a razão, ela é, no entanto, na nossa miséria humana, o único solo à disposição de onde possa brotar, naturalmente, essa mesma razão que lhe faz falta" (Gagnebin, 2005, p. 175-176).

Na perspectiva de Kant (2011), a educação teria como seu principal papel a imposição de uma disciplina à criança, de modo que ela passasse de um estado de selvageria para uma condição humanizada e polida, permitindo-lhe ascender à maioridade e à razão. Segundo o autor,

A selvageria consiste na independência de qualquer lei. A disciplina submete o homem às leis da humanidade $\mathrm{e}$ começa a fazê-lo sentir a força das próprias leis. Mas isso deve acontecer bem cedo. Assim, as crianças são mandadas cedo à escola, não para que aí aprendam alguma coisa mas para que aí se acostumem a ficar sentadas tranquilamente e a obedecer pontualmente àquilo que lhes é mandado, afim de que no futuro elas não sigam, de fato e imediatamente, cada um de seus caprichos (Kant, 2011, p. 13).

Entendida como infans, desprovida de linguagem, a infância detém, em potência, a capacidade da fala e a razão. Assim, caberia à educação efetuar essa potencialidade, transformando "[...] esses pequenos seres egoístas, tirânicos e choraminguentos em homens dotados de linguagem, isto é, capazes de pensar e agir racionalmente, de se tornar os cidadãos responsáveis e independentes de uma res publica" (Gagnebin, 2005, p. 176). Ora, essa noção da infância como uma etapa em que se ensina a criança a conter seus desejos e impulsos mais espontâneos com vistas a prepará-la para a vida social é bem evidenciada por Herbart (2014, p. 31), em seus escritos pedagógicos, ao afirmar que o governo das crianças é parte indispensável na educação geral, afinal: 
[...] permanecem na criança as sementes deste ímpeto cego, dos desejos rudes, que aumentam e até se fortalecem com os anos e, para que não orientem a vontade num sentido contrário ao da sociedade (a vontade que se ergue no meio deles), é necessário mantê-las constantemente sob uma pressão sempre tangível. O adulto e aquele que chegou à idade da razão assumem naturalmente com o tempo governarem-se a si próprios.

A compreensão da infância como estado de vir a ser, como infans e como uma fase de maior maleabilidade, mas também de vícios os quais requereriam o governo por parte dos adultos, constitui a noção de infância-quarentena. De acordo com tal concepção, portanto, a formação das crianças deveria dirigir-se rumo ao fim da infância - este estágio da vida que consistiria numa quarentena, num período destinado à transposição do estado de incompletude.

A imagem da infância singularizada diz respeito às concepções que tomam a criança como um sujeito peculiar, inocente e dotado de qualidades específicas. A educação, nesta perspectiva, é entendida como o conjunto de ações que tornam possíveis o pleno desenvolvimento da criança e o seu amadurecimento espontâneo; portanto, a confiança na razão migra para a valorização da natureza e de seus processos.

Do ponto de vista pedagógico, “[...] os papeis se transformam radicalmente: em vez de corrigir a natureza infantil e de querer, o mais rapidamente possível, a tornar adulta”, o que se almeja agora é “[...] escutar com atenção a voz da natureza na criança, ajudar seu desenvolvimento harmonioso segundo regras ditadas não pelas convenções sociais, mas oriundas da maturação natural das faculdades infantis" (Gagnebin, 2005, p. 177-178). Esse pensamento de matriz rousseauniana, impregnou o discurso educacional de modo a produzir uma pedagogia pautada no respeito à singularidade da criança e no enaltecimento de sua naturalidade, espontaneidade e inocência face à corrupção do mundo adulto, onde prevalecem as convenções, a racionalidade artificial e a inabilidade dos indivíduos em construir uma sociedade melhor. A respeito dessa visão, Snyders (1974, p. 89-90) assevera que, nessas teorizações pedagógicas:

O mundo adulto nada tem a oferecer como modelo válido à criança, porque esse mesmo mundo adulto seguiu um caminho inteiramente errado e avança para a perdição. Pelo contrário, a criança é o receptáculo de qualidades duma tal excelência que se bastam a si mesmas [...] Por um lado, o adulto representa uma decadência e de modo algum uma realização: 'a idade adulta é a petrificação' [...] Sair da infância é entrar nos tempos do declínio.

De acordo com Cambi (1999), conforme a pedagogia tornou-se puericêntrica, ela deslocou os seus esforços formativos e sua crença do ideal de homem racional e autônomo para o desenvolvimento da natureza infantil, passando a conceber a criança como 'o pai do homem'. Essa mudança de abordagem, “[...] produziu uma teorização pedagógica 
cada vez mais atenta para o valor da infância, para a função antropológica que esta veio a exercer (de renovação do homem, reconduzindo-o para formas mais espontâneas, mais livres, mais originárias)" (Cambi, 1999, p. 387).

Aliada à crença no potencial da educação escolar de transformar a sociedade, a imagem da espontaneidade e naturalidade da infância é, para Cambi, um dos pontos de gravidade da pedagogia a partir da época contemporânea; uma vez que essa representação da infância toma a criança como modelo de um novo tipo de homem, mais livre e genuíno, não autoritário e, portanto, concernente com o projeto de educação nas sociedades democráticas e liberais. A criança seria o modelo “[...] desse homem livre e liberado, subtraído às manipulações da sociedade, restituído às suas verdadeiras necessidades e assumido em toda a gama das suas potencialidades [...]" (Cambi, 1999, p. 392). Essa ideia é claramente identificada nas críticas de Neil (1973) à sociedade e projeto de formação das crianças no século XX. Nos excertos abaixo, verifica-se a descrença do autor no modelo de civilização de seu tempo e sua aposta na espontaneidade e autorregulação da criança como germe de uma nova organização social:

Um dia a humanidade poderá localizar todas as suas misérias, seus ódios, e suas moléstias, em sua forma particular de civilização, que é essencialmente contra a vida. Se rígida educação de caráter faz corpos rígidos - entorpecidos e cercados, em vez de serem vibrantes e vivos - parece lógico concluir-se que essa mesma inibição mortal inibirá a pulsação de todos os órgãos humanos necessários à vida. [...] A tragédia do homem está no fato de seu caráter, como do cão, poder moldar-se (Neil, 1973, p. 93).

Deixar que a criança se regule por conta própria implica uma crença na bondade da natureza humana, uma crença que não é, nem nunca foi pecado original (Neil, 1973, p. 98).

O puericentrismo assumido por uma grande parcela do pensamento pedagógico instaurou inovações e releituras constantes na pedagogia, já no século XX. E, a mudança de rota depreendida desse movimento deslocou radicalmente o foco da pedagogia que, da relação com a infância pautada num determinado referencial de adulto, passa a colocar-se a serviço da criança - vista como "o futuro e a esperança do homem, do homem novo" (Cambi, 1999, p. 393). Ou seja, para numerosas teorizações da área, não caberia mais à pedagogia pensar a formação da criança para o ingresso no mundo adulto, mas, atentar-se à natureza da criança em seu estado presente, tendo como premissa que a observância das especificidades daquele ser poderia, de alguma maneira, humanizar o homem.

Ora, independentemente das possíveis vantagens ou desvantagens da adoção de uma ou de outra representação da infância no interior do discurso da pedagogia - se é que é possível avaliar a constituição de uma imagem e a concepção a ela atrelada sob o prisma de ganhos e perdas -, é relevante salientar a transformação que ocorre no sentido 
da ideia de formação: enquanto a representação da infância-quarentena tem um determinado modelo de adulto como parâmetro para as relações educativas com a criança, a imagem da infância singularizada inverte essa lógica, elegendo a criança como matriz do novo homem, como modelo sob o qual ele deverá ser reprojetado.

A infância ensimesmada consiste na representação de um universo infantil quase que autorrealizado; dotado de um fim em si mesmo, o qual não se justificaria em relação às demais idades da vida - seja em direção à formação de certo tipo de adulto ou como fonte de inspiração de um novo estatuto de humanidade. Dessa forma, o termo ensimesmado não visa atribuir conotação pejorativa a esta imagem da infância, mas relaciona-se a uma abordagem que percebe a criança como um ser imerso em seu mundo e como sujeito produtor de uma cultura infantil ${ }^{3}$.

Enquanto especialistas de diferentes áreas têm anunciado, nas últimas décadas, um processo de degeneração da infância e diluição das fronteiras entre adultos e crianças, os quais promoveriam a adultização das crianças e a infantilização dos adultos; o que se observa em alguns discursos pedagógicos, talvez numa tentativa impetuosa de ressignificar a infância e demarcar-lhe o lugar social, é o delineamento da imagem de uma infância concentrada e voltada para si mesma. Isto é, se por um lado, a impressão que se tem é de uma indistinção entre as maneiras que adultos e crianças se vestem, se entretêm e consomem mercadorias, aliada à proclamada falta de imposição de limites ou à violência e abandono social dos infantes; por outro lado, a pedagogia tem cumprido, cada vez mais intensamente, o seu papel de promoção da infantilização das crianças, prolongamento da infância e individualização do sujeito da educação, enfocando a consideração de suas idiossincrasias e desenvolvimento cognitivo e afetivo-emocional. Neste contexto, erige-se a representação de uma criança que produz cultura e que é portadora de cidadania, ou seja, um ser que significa o mundo de um modo essencialmente diferente dos adultos e que assume o status de pequeno cidadão numa paradoxal relação de igualdade e diferença.

Ora, há que se fazer uma ressalva importante em relação às ideias acima citadas. Sabe-se que muitos desses estudos que se apoiam e defendem a noção de culturas infantis se circunscrevem no campo da sociologia da infância e que, como tais, estão sob os critérios avaliativos desta área específica, mas, sobretudo, do campo das ciências sociais. Com vistas a propor uma revisão crítica do conceito de socialização, o discurso sociológico sobre a infância tem se proposto a pensar as crianças como atores sociais ativos no processo de socialização e "não como destinatários passivos da socialização adulta" (Sarmento, 2008, p. 20). Essa atitude tem por objetivo estabelecer uma ruptura com os limites clássicos da sociologia que, de acordo com Sarmento (2008), analisava a criança apenas sob as categorias de aluno ou de delinquente. Assim, “[...] a Sociologia da Infância propõe o estabelecimento de uma distinção analítica no seu duplo objeto de estudo: as crianças como atores sociais, nos seus mundos de vida, e a infância, como categoria social do tipo geracional, socialmente construída" (Sarmento, 2008, p. 22). Essa 
Representações da Infância nos Discursos Pedagógicos

descrição muito geral e sucinta de um campo importante para a inovação dos estudos sobre a infância e que está em franco processo de ascensão é necessária para que se justifique a opção por considerar esses escritos na constituição da imagem de infância ensimesmada no interior dos discursos pedagógicos. Como vários autores dessa vertente - Régine Sirota, Gilles Brougère, William Corsaro e o próprio Manuel Sarmento, para citar alguns - resvalam, inevitavelmente, em temáticas referentes à educação ao abordarem as culturas da infância, muitos de seus conceitos passaram a compor o vocabulário dos pedagogos e foram incorporados aos discursos da pedagogia. Uma vez pensados sob a gramática dos discursos pedagógicos, tais conceitos são ressignificados pelo contexto da reflexão sobre a relação entre adultos e crianças na escola, sobre os modos de educar e de conduzir a infância. Portanto, é sob essa óptica específica e particular que é tratada a representação da infância produzida ou influenciada por este campo, deixando em suspensão as diferentes abordagens e correntes que o compõem. Logo, o valor sociológico desses estudos não compõe a pauta deste trabalho. Importa aqui a maneira como eles são incorporados pelos discursos pedagógicos e, segundo a lógica prescritiva e normativa que caracteriza a pedagogia, passam a constituir uma imagem que se tem da infância e consequentes modos de condução, para além da análise sociológica sobre a realidade de desigualdade e invisibilidade social das crianças anunciada por essa vertente de estudos.

Dito isso e retomando a argumentação sobre a representação da infância ensimesmada, é sabido que, desde o advento da pedagogia moderna e o desenvolvimento da psicologia e da medicina, a criança se tornou objeto de muitas teorizações e os saberes sobre ela aumentaram exponencialmente. A diversidade de saberes que possuímos sobre as crianças na atualidade, por vezes, as submete à clausura simbólica em um mundo que elegemos como especificamente delas. No entanto, ao mesmo tempo em que isso pode levar a crer num possível emparedamento da infância contemporânea - acompanhado da descaracterização do seu sentido moderno -, nota-se a expansão da idade pueril e o transbordamento das questões que envolvem o universo infantil para todos os setores da sociedade. A infância é, mais do que nunca, um assunto público.

Não são poucas as ações, nas últimas décadas, que se destinam a proteger as crianças da violência, do abandono, da truculência e do autoritarismo por parte dos adultos. Para além da proteção em relação às ameaças do mundo público, de uns anos para cá, têm sido discutidas medidas que visam legislar sobre o ambiente privado da criança, como é o caso da lei da palmada. Isto demonstra o quanto as questões que envolvem a infância fazem parte da agenda política e dos debates da sociedade civil. Porém, tal como foi anunciado, a situação real das crianças não é o tema sobre o qual este artigo versará, importa aqui discorrer sobre as imagens da infância que se constituem no âmbito dos discursos pedagógicos. Por isso, para discutir a complexidade desta infância ensimesmada e os dilemas que envolvem a compreensão pedagógica da 
infância na contemporaneidade, faz-se necessário destacar que a educação, familiar ou escolar, é, antes de tudo, o modo pelo qual os adultos se relacionam com este tipo peculiar de ser que é a criança e com seu processo de formação e de inserção na cultura.

De acordo com Renaut (2002, p. 14), grande parte das questões levantadas pela educação diz respeito às transformações na representação da infância, as quais se produziram "[...] à medida que as sociedades se tornaram democráticas e que se basearam, já não (tal como as sociedades antigas) nos valores da tradição e da hierarquia, mas nos da liberdade e da igualdade". Na abordagem do autor, o ponto fulcral da crise na educação -, isto é, da crise na relação intergeracional entre adultos e crianças - é a dificuldade de conciliação entre a complexidade da alteridade da criança e a modernização das representações do outro, proveniente da eleição do princípio da igualdade como base das relações sociais na modernidade ${ }^{4}$. Em outras palavras, para Renaut, a igualdade moderna coloca um paradoxo em relação à alteridade da infância uma vez que, embora a criança passe a ser tomada como um igual quanto aos direitos, a sua imaturidade e dependência inviabilizam a efetivação deste princípio; isto é, ainda que seja vista como possuidora de igualdade de direitos, a criança tem como marca constituitiva de sua relação com os adultos a diferença que caracteriza sua condição e a exigência de proteção.

Ao inventar a infância, a organização estatal e as democracias liberais, os modernos criaram um dispositivo pelo qual a criança ascenderia à comunidade dos iguais: a educação passou a ser a promissória que lhe garantiria a igualdade e a liberdade. A promessa de obtenção de tais estatutos após o processo de educação e, portanto, com o ingresso na vida adulta está na origem do ideário da escola republicana. No entanto, o equilíbrio moderno entre autoridade e tutela dos adultos em relação às crianças e o direito indistinto à igualdade e à liberdade assegurado a todos - ainda que virtualmente - fragilizou-se com o desenvolvimento da modernidade. À medida que a identificação da criança como portadora de direitos adentrou o âmbito familiar e escolar, as relações entre igualdade e diferença, liberdade e autoridade ou tutela foram fortemente tensionadas no contexto educacional. Dessa maneira, “[...] este processo moderno de educação na autonomia e na identidade comum é [...] complexificado e densificado na idade contemporânea, por diversas razões que respeitam àquilo que caracteriza a fase mais recente da dinâmica democrática" (Renaut, 2002, p. 18); já que, conforme a representação do outro como semelhante se fortaleceu na sociedade, o valor da diferença foi o que passou a gerar conflitos.

A respeito dessa tentativa moderna de igualizar todos os indivíduos e relações sociais e o desencadeamento de tensões que envolvem a questão da diferença entre os sujeitos e grupos aos quais pertencem, Renaut (2002, p. 18-19) afirma, no que tange à educação, que:

Vivemos, sem dúvidas, o momento em que esta tensão, que se introduziu durante estes últimos decênios na re-

Educação \& Realidade, Porto Alegre, v. 42, n. 1, p. 299-321, jan./mar. 2017. 
Representações da Infância nos Discursos Pedagógicos

lação com a criança, atingiu a intensidade mais forte, a ponto de fragilizar todas as referências conhecidas, na escola e no seio da família. É-nos fornecido um indício desta tensão, se pensarmos, por exemplo, na maneira como todas as conquistas da antropologia, ou da psicologia, de há trinta anos para cá, nos convidam a aprofundar a diferença, a dissemelhança da criança, ao passo que, por outro lado, toda a apreensão jurídica da infância nos conduz a imaginarmos, cada vez mais, a sua identidade de direito.

A ênfase progressiva das ciências humanas na dessemelhança da criança e nos valores intrínsecos da infância remete à questão da pedagogia contemporânea. Como bem destaca Renaut, o desequilíbrio entre a apreensão jurídica da criança na atualidade - calcada na igualdade de direitos - e a produção de saberes sobre a infância - fundada na diferença deste grupo em relação aos demais - ajudam a deflagrar uma crise intensa no âmbito da educação.

A evidenciação da diferença da criança em relação ao adulto temse mostrado um movimento crescente no âmbito da pedagogia. Essa celebração da infância no contexto pedagógico é tão intensa que, nos últimos anos, tem-se visto o fortalecimento de uma vertente denominada pedagogia da infância. Com foco na teorização sobre a educação da primeira infância, esta pedagogia revela em seus discursos, para além de uma reconhecida defesa dos direitos e proteção da criança, a representação dessa infância que gira em torno de si, que se introspecta para dentro de seu universo e se afasta da relação com o mundo dos adultos. Sobre este segmento teórico específico, Arce (2012, p. 142-143) afirma que:

Pode-se dizer que esta pedagogia faz do adulto um escravo da infância transformada em fetiche dos educadores. [...] Parece-me que a pedagogia da educação infantil não somente quer preservar a criança da educação escolar, como também quer fazer da infância um refúgio distante das mazelas produzidas pela sociedade contemporânea. Há um ar de nostalgia da pureza perdida pela sociedade, mas preservada pela infância. Defender a pedagogia da infância seria como defender o retorno a essa pureza perdida.

A ideia da infância como o reduto de uma pureza perdida pelo adulto e que, em certa medida, deve ser protegida das mazelas do mundo e da própria intervenção deste adulto - tida como castradora e tolhedora das manifestações espontâneas e legítimas da criança - é, segundo a autora, um fetiche para os educadores. A compreensão da ideia de fetiche ajuda a perceber em quais aspectos essa imagem da infância se aproxima e potencializa a noção de infância singularizada.

De acordo com Duarte (2012), a palavra fetiche é utilizada em língua portuguesa por influência do vocábulo francês fétiche, que significa feitiço. No dicionário Aurélio, fetiche é definido como "[...] objeto animado ou inanimado, feito pelo homem ou produzido pela natureza, ao qual se atribui poder sobrenatural e se presta culto" e, fetichismo signi-

308 Educação \& Realidade, Porto Alegre, v. 42, n. 1, p. 299-321, jan./mar. 2017. 
fica "[...] culto de objetos materiais, considerados como encarnação de um espírito, ou em ligação com ele, e possuidores de virtude mágica" (Duarte, 2012, p. 1). Assim, fetiche e fetichismo são fenômenos que possuem origem religiosa, no sentido que envolve a sacralização, culto e adoração a algo produzido pela natureza ou pelo homem.

O entendimento da infância contemporânea como um fetiche para os educadores traz à baila a imagem de uma infância que não é somente valorizada pelos seus atributos e especificidades, mas que seria alçada como objeto de culto secular. É como se a infância se revestisse de sacralidade - não do ponto de vista religioso, mas como algo venerável e imaculado - e fosse representada em oposição ao mundo adulto, entendido como profano e corrompido. Além disso, a representação da infância associada à pureza, inocência e espontaneidade que, como se sabe, é uma construção simbólica dos adultos em relação às crianças, passa a ser naturalizada no discurso pedagógico, como se tratassem de atributos inatos e universais das crianças ou se manifestassem como símbolos inerentes às relações que elas tecem entre si no grupo.

A visão da infância fetichizada como paraíso perdido dos adultos implica, na concepção da autora, uma inversão na qual "[...] passa-se a considerar que é a criança quem humaniza o adulto em vez de este humanizar aquela" (Arce, 2012, p. 139). Mais do que isso, ao pensar a infância como um universo simbólico e cultural independente e dotado de um valor que se sobrepõe ao do mundo adulto, a pedagogia concebe a criança e as linguagens e saberes a ela atribuídos como sentido último de suas teorizações, desconsiderando a transitoriedade cronológica da infância. Ou seja, ainda que a intenção seja valorizar a corporeidade, os símbolos, as representações e saberes da infância, pensá-la como um estágio da vida autônomo, afeito às relações existentes unicamente em seu universo particular, despreza, por vezes, o fato de que as crianças crescem e tornam-se adultos.

De qualquer modo, o recrudescimento dessa noção pedagógica puericêntrica é apenas um aspecto daquilo que se entende aqui como uma imagem ensimesmada da infância e que, segundo esta abordagem, torna-se cada vez mais patente na contemporaneidade. A representação da infância, nos tempos atuais, traz em seu cerne a tensão entre igualdade e diferença, o que significa que tais princípios não se repelem, mas se relacionam entre si. Nesse sentido, é possível afirmar que o próprio movimento de significação e valorização da infância por sua dessemelhança revele não apenas a transformação de uma ideia, mas também a tentativa de demarcar a diferença onde as indistinções parecem avançar. Isso pode ser tomado como o sintoma do declínio de certo tipo de relacionamento da sociedade para com as crianças, uma vez que "[...] quando um artefato social fica obsoleto se transforma num objeto de nostalgia e contemplação" (Postman, 1999, p. 19).

É a partir dessa ideia de obsolescência que importantes trabalhos na área das humanidades buscam alertar para o desaparecimento ou fim da infância em nossos tempos, destacando a conspícua diluição da linha divisória entre adultos e crianças. Publicado nos Estados Unidos 
Representações da Infância nos Discursos Pedagógicos

nos anos 1980, o livro de Neil Postman, O Desaparecimento da Infância, é uma das principais referências sobre a tese de que a noção moderna de infância está em processo de perecimento. A respeito da maciça influência deste livro nos meios acadêmicos e de sua redescoberta por estudiosos da infância na primeira década do século XXI, Narodowski (2011, p. 103) afirma que isso "[...] marca a preocupação e, muitas vezes, desorientação por um fenômeno que ocupa um lugar cada vez mais importante nos debates sociológicos contemporâneos: as mudanças no status da infância moderna e as predições a respeito de sua extinção" 5 .

A referida obra dedica-se a refletir sobre o âmbito da comunicação social, debruçando-se sobre a relação da sociedade moderna e contemporânea com as tecnologias da informação e o papel destas últimas no processo de invenção e desaparecimento da infância. $\mathrm{O}$ percurso empreendido por Postman para reconstruir as bases da invenção da infância moderna lhe serve para fundamentar sua tese de que essa infância, que se estabeleceu como operação de segregação e simbolização de uma etapa formativa, está desaparecendo. E são muitos os indícios que o autor apresenta para justificar seu argumento acerca do desaparecimento da infância: decadência dos jogos infantis, indistinção entre vestuário tipicamente infantil e de adultos, erotização das crianças, aumento dos crimes e delinquência juvenis.

Ora, este trabalho considera como hipótese mais plausível a ocorrência de um processo de transformação da noção de infância, o qual, embora caminhe para supressão de algumas marcas distintivas entre adultos e crianças, amplia espaços socioculturais em que o específico da idade pueril passa a ter lugar e expressão. Ou seja, apesar da perplexidade apresentada por Postman ser legítima e de sua crítica ser certeira, crê-se que seja temerário afirmar que a infância está em curso de desaparição. O que abordagens como a do autor apontam são as insuficiências explicativas que o conceito moderno de infância apresenta no contexto atual, visto que sua função de delimitação da fronteira geracional tem perdido em significação com as mudanças nas sociedades ocidentais e ocidentalizadas (Peña, 2008).

O paradoxo da representação da infância contemporânea se apresenta, de um lado, pelo esgarçamento da linha divisória entre as gerações e a perda progressiva do significado de dicotomias como adulto/criança, menor de idade/maior de idade, educador/aprendiz, responsável/tutelado, e; do outro lado, pela intensificação da noção de diferença da criança, a ampliação da oferta de produtos e serviços voltados à infância e o aumento da produção de saberes específicos sobre este grupo. Segundo Peña (2008, p. 41),

Em certa medida, a infância não desaparece, mas sim se converte em meio para erodir o infantil. Dito com outras palavras, os critérios de demarcação entre infância e vida adulta se racham - o infantil se esfumaça - e a infância, por sua parte, coloniza e se expande - se ressignifica - nos âmbitos do social e do cultural. [...] A cotidianidade se enche de símbolos, nos quais se outorgam características 
divinas e sagradas às crianças no sentido de deidades redentoras ${ }^{6}$

É no interior deste panorama de mutações da representação da infância na pedagogia que se identifica a indissociabilidade entre ambas, o que aponta o constante processo de significação e ressignificação que se dá na relação entre pedagogia e infância, isto é, na imagem do infantil produzida pelos discursos pedagógicos. Nesse sentido, entendese que as rupturas que ocorrem entre uma determinada representação da infância e a constituição de outra se associam ao próprio projeto de modernização da sociedade e aos dilemas que se colocam, a partir disso, no âmbito da educação.

\section{Representações da Infância e Regimes de Historicidade}

Ao comentar a centralidade da noção social do tempo, Agamben (2008, p. 111) afirma que "[...] toda cultura é, primeiramente, uma certa experiência do tempo, e uma nova cultura não é possível sem uma transformação desta experiência”. Segundo o autor, como dispomos da experiência e não da representação do tempo, nossa mente se vale de imagens espaciais para concebê-lo. Um exemplo disso é que a concepção temporal da antiguidade greco-romana era circular e contínua, o que significa que, para essa cultura, o tempo não tinha direção. Ou seja, não tinha "[...] início, nem centro, nem fim, ou melhor, ele os [tinha] somente na medida em que, em seu movimento circular, [retornasse] incessantemente sobre si mesmo" (Agamben, 2008, p. 112).

Em contrapartida, a imagem que guiava a concepção cristã do tempo era a de uma linha reta. Diferentemente da noção de um tempo sem direção da cultura clássica, este tempo tinha um rumo e um sentido: estendia-se do ponto inicial da criação ao fim do mundo, tendo um ponto de referência central no nascimento de Cristo - que caracterizava o próprio desenvolvimento do tempo como progressão do pecado original à redenção final. Nessa ideia de tempo retilíneo que se pode conceber a novidade como aquilo que acontece uma única vez em oposição à eterna repetição do ciclo da vida e do mundo.

A concepção do tempo na idade moderna, de acordo com Agamben (2008, p. 117), “[...] é uma laicização do tempo cristão retilíneo e irreversível, dissociado, porém, de toda ideia de um fim e esvaziado de qualquer sentido que não seja o de um processo estruturado conforme o antes e o depois". Já que a história da salvação tornou-se mera cronologia, o autor afirma que um resquício do sentido pôde ser salvo apenas com a introdução da ideia de progresso.

Assim, como cada cultura corresponde a um tipo de experiência do tempo e a mudança de tal experiência condiciona e desencadeia transformações socioculturais, é possível afirmar que as mutações ocorridas na modernidade trazem em seu interior modificações na relação das sociedades com o tempo. A maneira como os sujeitos, na coletividade, apreendem e engrenam as noções de passado, presente e futuro, constituindo significados, relações e experiências no tempo

Educação \& Realidade, Porto Alegre, v. 42, n. 1, p. 299-321, jan./mar. 2017.

311 
define o regime de historicidade que fundamenta uma sociedade em determinado momento de sua história.

Este conceito de regime de historicidade, proposto por François Hartog, consiste num instrumento de análise que permite "[...] colocar em foco modos de relação com o tempo: formas da experiência do tempo [...] [e] maneiras de ser no tempo" (Hartog, 2013, p. 29). Não se trata, pois, de abordar a imagem associada ao tempo, mas sim as experiências que se desenvolvem em sua extensão. Daí o termo historicidade, que expressa o modo como um indivíduo ou coletividade se instaura e se desenvolve no tempo, ordenando e dando sentido às suas experiências por meio das categorias de passado, presente e futuro.

Considerando essa concepção de tempo retilíneo, a noção de regime de historicidade auxilia a pensar sobre as mutações que ocorreram na própria experiência temporal das sociedades modernas, possibilitando a análise da condição contemporânea e as relações estabelecidas com as categorias de passado, presente e futuro em outros períodos da história. A ênfase incide, sobretudo, "[...] sobre as categorias que organizam essas experiências e permitem revelá-las, mais precisamente ainda, sobre as formas ou os modos de articulação dessas categorias ou formas universais [...]" (Hartog, 2013, p. 39). Desse modo, entendese que a maneira como essas categorias são operacionalizadas, em determinadas épocas e sociedades, possibilita a análise e percepção do deslocamento de uma ordem do tempo, uma vez que tais categorias são, simultaneamente, de ação e de pensamento.

Ao analisar as transformações na forma de relacionamento com o passado e o futuro na modernidade, Koselleck (2006) afirma que a distância entre experiência e expectativa aumenta progressivamente, estabelecendo-se como marca constitutiva do moderno. Segundo o autor, o tempo histórico é produzido por esta distância entre o espaço da experiência e o horizonte da expectativa, isto é, pela tensão que se dá entre ambos os polos. Assim, "[...] para Koselleck, a estrutura temporal dos tempos modernos, marcada pela abertura do futuro e pelo progresso, caracteriza-se pela assimetria entre a experiência e a expectativa" (Hartog, 2013, p. 39), sendo que, do século XVIII para cá, o desequilíbrio entre essas dimensões não cessou de crescer, potencializado pelo efeito da aceleração do tempo.

Experiência e expectativa são categorias que compõem um par de conceitos indissociável, de modo que "[...] não há expectativa sem experiência, não há experiência sem expectativa” (Koselleck, 2006, p. 307). A experiência é o passado atualizado, aquele no qual se fundem a compreensão racional e as formas inconscientes de comportamento que constituíram os acontecimentos incorporados pela memória e que podem ser recordados. Ademais, "[...] na experiência de cada um, transmitida por gerações e instituições, sempre está contida e é conservada uma experiência alheia" (Koselleck, 2006, p. 310). Da mesma maneira, a expectativa possui dimensão pessoal e interpessoal e realiza-se também no hoje, constituindo-se como futuro presente. Ela é formada por esperança e medo, vontade e desejo, inquietude, anseio, mas também 
pela análise prospectiva racional, pela curiosidade. Como um porvir presente, a expectativa está voltada "[...] para o ainda-não, para o não experimentado, para o que apenas pode ser previsto" (Koselleck, 2006, p. 310).

Assim, é possível dizer que a experiência advinda do passado é espacial, porque ela aglomera acontecimentos e recordações para formar um todo em que diferentes recortes de tempos anteriores estão concomitantemente presentes, não havendo referência a antes e depois. Ou seja, a experiência não é ordenada ou mensurada cronologicamente, "[...] porque a cada momento ela é composta de tudo o que se pode recordar da própria vida ou da vida dos outros" (Koselleck, 2006, p. 311). Portanto, ela não estabelece continuidade como uma sequência de acontecimentos que são adicionados, de maneira cronológica, ao passado.

A expectativa, por sua vez, é representada pela metáfora do horizonte. Isso é assim porque ela é vislumbrada adiante, num futuro que pode se abrir para um novo espaço de experiência que, embora se espere ou se projete como plano, ainda não pode ser contemplado. Essa imagem da linha do horizonte significa que, "[...] a possibilidade de se descobrir o futuro, apesar de os prognósticos serem possíveis, se depara com um limite absoluto, pois ela não pode ser experimentada" (Koselleck, 2006, p. 311). De maneira geral, as expectativas são formuladas a partir das experiências, podendo ser confirmadas ou não no futuro - o que repercute na reordenação do próprio material do vivido, isto é, na reconfiguração das experiểncias. $\mathrm{O}$ acontecimento não previsto e não esperado rompe a linha do horizonte de expectativa e institui uma nova experiência, reorganizando ambas as dimensões.

Essa relação entre experiência e expectativa - que tornava o diagnóstico imprescindível para a formulação do prognóstico e a realização ou não da previsão fundamental para a reordenação dos conteúdos do passado - desequilibrou-se na época moderna. Abriu-se um fosso entre experiência e expectativa. O caráter da distância que se estabeleceu entre ambas e os modos de tensão instaurados são o que a ideia de regime de historicidade ajuda a analisar. Em outras palavras, a relação que as sociedades modernas tecem com as categorias de passado, presente e futuro alteram-se conforme a distância entre experiência e expectativa se aprofunda.

Um exemplo disso é que, enquanto a doutrina escatológica cristã impunha rígidos limites ao horizonte de expectativa, futuro e passado permaneciam atrelados. A revelação bíblica envolvia a tensão entre experiência e expectativa de tal modo que elas conservavam-se indissociáveis, afinal, o que organizava as projeções futuras era a espera pelo fim do mundo - que havia sido anunciado como uma promessa do passado. A experiência cristã, que se traduziu em tradição, era o terreno sobre o qual se faziam as profecias do fim, ou seja, era o espaço de onde se deslumbrava a linha da expectativa. As projeções que se lançavam para além da experiência vivida não diziam respeito a este mundo, referiamse ao transcendental, àquilo que era extramundano. Assim, o não cum- 
primento de uma profecia podia culminar em sua reiteração, servindo como prova de que a enunciação apocalíptica do fim do mundo, uma vez não realizada, tinha uma probabilidade maior de concretizar-se da próxima vez. Com isso, "[...] a estrutura repetitiva da expectativa apocalíptica garantia que as experiências contrárias, aqui embaixo, fossem imunizadas" (Koselleck, 2006, p. 315-16).

Entretanto, à medida que os cálculos em relação ao apocalipse foram adiando o dia do fim e com a cessão das guerras civis religiosas do século XVII, a discussão sobre o tema foi sendo abandonada e as próprias expectativas cristãs foram exterminadas pouco a pouco. $\mathrm{O}$ avanço das ciências e a descoberta do Novo Mundo ajudaram a constituir, a princípio lentamente, uma consciência de história universal e uma projeção para o futuro mais afastada da experiência do passado. Com o enfraquecimento da crença nas profecias do fim dos tempos, um novo horizonte de expectativa se abriu para a modernidade sobre a forma da ideia de progresso. Dessa maneira,

\begin{abstract}
Do ponto de vista da terminologia, o 'profectus' espiritual foi substituído por um 'progressus' mundano. O objetivo de uma perfeição possível, que antes só podia ser alcançado no além, foi posto a serviço de um melhoramento da existência terrena, que permitiu que a doutrina dos últimos fins fosse ultrapassada, assumindo-se o risco de um futuro aberto. Por último, o objetivo da perfeição foi temporalizado, primeiramente por Leibniz, e trazido para o nível do acontecer mundano: 'progressus est in infinitum perfectionis' [o progresso é para a perfeição infinita]. [...] Desde então toda a história pôde ser concebida como um processo de contínuo e crescente aperfeiçoamento; apesar das recaídas e rodeios, ele teria que ser planejado e posto em prática pelos homens. [...] Em suma: a partir de então o horizonte de expectativa passa a incluir um coeficiente de mudança que se desenvolve com o tempo (Koselleck, 2006, p. 316-17).
\end{abstract}

A substituição da doutrina da profecia pela ideia de progresso, como diretriz do tempo, balizou-se no objetivo de promover o aperfeiçoamento da sociedade e de alcançar a perfectibilidade humana. Desconectada da perspectiva do fim do mundo, a expectativa do progresso abre a dimensão do futuro e de suas potencialidades. Destarte, em contraposição aos períodos e sociedades anteriores que depositavam sua esperança na experiência do passado - a qual se constituía como modelo para o presente e como medida para as projeções futuras -, as sociedades modernas, a partir de então, voltam-se para o futuro e nele identificam a luz que ilumina as ações do presente e lança sombras sobre o passado - que já não é mais reconhecido como parâmetro para as decisões e os dilemas que se colocam no âmbito das relações sociais e da política.

A crença no progresso e a transformação ativa do mundo desestabilizaram a relação que as sociedades modernas estabeleciam, até então, com as categorias de passado, presente e futuro, de modo que 
o espaço da experiência deixou de limitar o horizonte da expectativa. Nesse contexto, as expectativas emanciparam-se das experiências e, ao passo que o futuro se abria em possibilidades antes impensadas, o passado também se estendia como um reservatório de conteúdos e saberes ultrapassados. Segundo Hartog (2013), esse regime de historicidade futurista que se instalou nas sociedades modernas e que perdurou, ainda que tenha passado por transformações e ajustes, até o século XX, chegou a desvalorizar o passado e a sacrificar o presente em nome da perfectibilidade e do progresso, que se acreditava residir no futuro. Com isso, passou-se a entender o passado como algo a ser constantemente superado e o presente, por vezes, como a mera "véspera do futuro" (Hartog, 2013, p. 33).

A relação com a infância, neste contexto, também sofreu mudanças. Se a infância nasce, a princípio, entendida como um período de segregação em relação aos adultos para o desenvolvimento e inserção na cultura, nesta virada da modernidade para o futuro, ela passa a ser concebida como uma idade da vida que encarna a possibilidade de efetivação do progresso. Ou seja, se numa acepção inicial a infância era reconhecida como a idade da falta, a qual seria suprimida aos poucos pela posse dos saberes da tradição, com a ascensão da noção de progresso, ela torna-se o símbolo do novo e o germe da mudança.

Neste primeiro estágio do regime de historicidade moderno, em que a crença no progresso sustentava um forte otimismo e esperança no futuro, a criança foi pensada como projeto, como a versão aperfeiçoada do indivíduo. Ainda que a referência inicial tenha sido a formação de um adulto letrado, cidadão e racional esperava-se que a criança do presente viesse a ser o sujeito aprimorado do futuro. Essa ideia se constituiu, de certo modo, como um dos pilares do programa da educação republicana, o qual visava à formação do homem novo - o homem aperfeiçoado.

A crença na criança como matriz de uma nova sociedade e como promessa de um futuro afortunado se intensifica à medida que progresso e avanço deixam de ser tomados, necessariamente, como sinônimos. Isso significa que, conforme a crença no progresso como equivalente à evolução ética e política dos sujeitos - e não apenas como desenvolvimento tecnológico e científico - começou a ser colocada em xeque, os adultos se voltaram para as crianças na esperança de que elas seriam os únicos agentes capazes de construir um novo mundo, de realizar o projeto de modernidade que eles não foram suficientemente competentes para efetivar.

Ora, é evidente que, desde a invenção moderna da infância, as crianças passaram a ser vistas como apostas para o futuro, como seres sobre os quais repousa um grande investimento formativo por parte da sociedade. O que é importante destacar é o movimento que as torna de objeto a sujeito da mudança. E este processo se dá de maneira paulatina na educação - um dos setores da sociedade em que, de acordo com Arendt (2003, p. 237), a modernização foi mais tardia -, atingindo o cerne da pedagogia com os discursos de renovação da escola e do ensino, no início do século XX. 
Representações da Infância nos Discursos Pedagógicos

Na intenção de estabelecer uma linha divisória entre a educação até então vigente e a nova educação proposta, vários teóricos da pedagogia se dedicaram a demonstrar as diferenças fundamentais entre a pedagogia tradicional - por eles assim nomeada - e as pedagogias renovadas ${ }^{7}$. John Dewey, um dos principais expoentes dessa tendência educacional renovada e também um dos autores mais criteriosos de tal corrente pedagógica, exprime com clareza a questão da relação que ambas as pedagogias estabelecem com as novas gerações e o tempo. Ao definir a educação segundo a pedagogia tradicional, Dewey (1976, p. 4) destaca que, nesta abordagem pedagógica, o conteúdo "[...] consiste de corpos de informação e de habilidades que se elaboraram no passado" e que "[...] a principal tarefa da escola é, portanto, transmiti-los à nova geração”. Ele ainda diz que o objetivo precípuo da educação tradicional "[...] é preparar o jovem para as suas futuras responsabilidades e para o sucesso na vida, por meio da aquisição de corpos organizados de informação e de formas existentes de habilitação, que constituem o material de instrução" (Dewey, 1976, p. 4).

Em sua crítica a tal modelo educacional, o autor afirma que, para a pedagogia tradicional:

\begin{abstract}
Aprender significa adquirir o que já está incorporado aos livros e à mente dos mais velhos. Considera-se ainda o que se ensina como essencialmente estático. Ensinase um produto acabado, sem maior atenção quanto aos modos e meios por que originalmente assim se faz, nem também quanto às mudanças que seguramente irá sofrer no futuro. Trata-se de produto cultural de sociedades que supunham o futuro em tudo semelhante ao passado e que passa a ser usado como alimento educativo de uma sociedade, em que a regra e não a exceção é mudar (Dewey, 1976, p. 6)
\end{abstract}

A definição de Dewey sobre a tradição pedagógica aponta a vigência do regime de historicidade que ainda mantinha a vinculação entre o espaço de experiência e o horizonte de expectativas, uma vez que, a formação das novas gerações era pensada na relação entre os conteúdos do passado como referência para a construção e atuação no futuro. A esse modelo formativo que, de acordo com o autor e os demais teóricos das pedagogias renovadas, não se adequaria mais às demandas da época contemporânea, é proposta uma educação mais concernente com um mundo em constante transformação. Nesse sentido, "[...] à preparação para um futuro mais ou menos remoto opõe-se aproveitar-se ao máximo das oportunidades do presente; a fins e conhecimentos estáticos opõe-se a tomada de contacto com um mundo em mudança” (Dewey, 1976, p. 7).

Um aspecto relevante a ser enunciado é que as pedagogias renovadas se originaram, em sua maioria, na primeira metade do século $\mathrm{XX}$ - período em que a fé no progresso começou a ser questionada. $\mathrm{O}$ cenário político e social desta época, como sabemos, foi marcado por guerras, depressão econômica e muitas incertezas. Neste contexto problemático em que, pouco a pouco, as evidências pareciam atestar que

316 Educação \& Realidade, Porto Alegre, v. 42, n. 1, p. 299-321, jan./mar. 2017. 
a promessa iluminista de emancipação humana pela razão não havia conduzido os homens para um mundo melhor, a infância passa a ser representada, num retorno ao ideal rousseauniano, como símbolo de inocência e como possibilidade de redenção dos seres humanos. Face à aparente incapacidade dos adultos de resolverem seus conflitos politicamente e de constituírem uma sociedade pautada na igualdade e na liberdade, agora, a fé na criança devolvia aos mais velhos a esperança no futuro e na perfectibilidade humana.

No interior de várias teorizações das pedagogias renovadas, esse regime futurista se manifestou sob um discurso reformista da sociedade. Ou seja, a representação da infância em tais discursos incorporava também um desejo de mudança da sociedade, de formação das crianças para um novo projeto sociopolítico. Em seu ensaio sobre A Crise na Educação, Arendt (2003) destaca essa característica das pedagogias renovadas de conceber a educação como instrumento da política, isto é, de pensar que a construção de um novo mundo deve ser realizada a partir das novas gerações. Nesta mesma direção, Legrand (1970, p. 6, grifos nossos), ao discutir os discursos de tais pedagogias, afirma que:

\begin{abstract}
Se a criança vale, é porque não é ainda deformada por uma sociedade pervertida. Ela carrega consigo as garantias de uma sociedade melhor. A maioria dos sectários da educação nova transfere para o nivel do ato pedagógico sua recusa à sociedade estabelecida e sua esperança de fundar uma ordem social nova. [...] A mudança procura pelo homem, e a criança, em sua pureza e sua ingenuidade primeira, carrega as promessas e a possibilidade de uma ordem nova. A verdadeira revolução é, para eles, uma revolução pacífica que a ação pedagógica prepara. [...] A criança é o ser de amanhã, disponível para todos os progressos, portadora natural das esperanças de uma sociedade nova ${ }^{8}$.
\end{abstract}

A noção da infância como promessa da instauração de uma nova ordem social perdura até a atualidade e impregna os discursos da sociedade civil e a propaganda política. No entanto, cada vez mais, a impressão que se tem é que o porvir no qual as crianças realizarão o sonho de um mundo melhor está muito próximo, logo ali, à nossa porta. Na verdade, para muitos, o futuro já chegou. Ora, o coeficiente de mudança que fora acrescentado ao horizonte de expectativas, como foi dito, implicou a aceleração progressiva do tempo. Com isso, a partir da segunda metade do século anterior, notou-se que "[...] o futuro começava a ceder terreno ao presente, que ia exigir cada vez mais lugar, até dar a impressão recente de ocupá-lo por inteiro. Entrávamos então em um tempo de supremacia do ponto de vista do presente: aquele do presentismo, exatamente" (Hartog, 2013, p. 142).

Embora a crítica ao progresso não implique uma promoção automática do presente, ela, certamente, introduziu a dúvida a respeito do caráter necessariamente positivo da marcha para o futuro. Dessa forma, ainda que o futurismo não tenha sido totalmente descartado, as catástrofes do século passado fizeram com que as sociedades questionassem a noção de que não apenas a ciência e a tecnologia progridem 
Representações da Infância nos Discursos Pedagógicos

com o passar do tempo, mas que também os homens se desenvolvem social, política e eticamente com o passar das gerações. Nesse sentido, Hartog (2013, p. 141) destaca que o século XX aliou futurismo e presentismo, sendo que, num primeiro momento, foi "futurista com paixão [e] com cegueira" e, pelo menos em suas últimas três décadas, foi muito mais presentista.

A expansão progressiva do presente e seu alargamento exagerado têm como força motriz o rápido desenvolvimento e as crescentes exigências da sociedade atual. Pautada no consumo e na geração de necessidades, essa sociedade torna, muito rapidamente, as inovações tecnológicas obsoletas e transforma as pessoas em seres supérfluos. Nesse contexto, "[...] produtividade, flexibilidade, mobilidade tornam-se as palavras-chave" (Hartog, 2013, p. 148) de um mundo em que tudo vira mercadoria e que, por estar imerso na lógica da mudança constante e da efemeridade, não dispõe de tempo para que as novas experiências decantem e os sujeitos possam extrair-lhes algum sentido.

A ligeireza das mutações é uma marca da época atual. Entretanto, o fato de tantas mudanças ocorrerem em um ritmo cada vez mais acelerado propõe um paradoxo em relação à condição vigente: “[...] nunca vivemos tantas mudanças e nunca fomos tão incapazes de mudar" (Silva, 2008, p. 154). A experiência de um tempo marcado pela velocidade e pela variação, em nossa sociedade, tem sido equivalente à indiferença, à previsibilidade do cotidiano. É como se as mudanças tivessem se tornado rotina e, em virtude disso, nos atingissem apenas como passageiros no curso da experiência histórica e não como agentes. Isso, porém, não ocorre porque exista uma continuidade histórica tão confiável ao ponto de não nos despertar inquietações frente ao inesperado. Pelo contrário, na contemporaneidade, o devir histórico tem sido surpreendente ao ponto de constituir-se, muitas vezes, como ameaça ou como a realização do absurdo, daquilo que não pudera ser imaginado.

O paradoxo da velocidade das mutações em um mundo no qual as pessoas, de modo geral, sentem-se incapazes de mudar ou serem afetadas pela novidade torna-se um problema no campo da educação, uma vez que, a relação entre as gerações, neste contexto, perde a referência no passado e no futuro. Se a certeza de que o mundo muda para continuar o mesmo se fortalece em um regime presentista, as crianças já não são vistas necessariamente como promessa, mas como aquilo que são em seu estado presente. Isso significa que, diante deste quadro, a representação de uma infância concentrada em si aparece como decorrência de uma sociedade caracterizada por um presente maciço e hipertrofiado.

Ora, se o espaço das experiências já não é mais referência e se o horizonte de expectativas é alcançado por um presente que se estende continuamente em direção ao futuro, tornando efêmeros os momentos e as coisas; pensar a infância como um universo quase que autorrealizado e dotado de valor em si - uma infância ensimesmada-parece concernente com uma sociedade em que grande parte dos adultos percebese incapaz de projetar a si e a outra realidade. 


\section{Notas}

1 Tradução nossa: ‘[...] ha sufrido una compleja evolución-transformación que ha dibujado una parábola, es decir, un primer itinerario de crecimiento, expansión y luego de declive-transformación que se está cumpliendo bajo nuestros ojos'.

2 O termo 'representação' é utilizado aqui como sinônimo de 'imagem' ou 'noção'. Assim, o uso que fazemos desses termos abarca um sentido mais ordinário e corriqueiro de tais palavras, não se referindo a um conceito específico. De acordo com o dicionário Caldas Aulete (2015, online), representação, dentre outros significados, refere-se ao 'processo por meio do qual a mente presentifica a imagem, ideia ou conceito de um objeto apreendido pelos sentidos, imaginação, memória, ou concebido pelo pensamento’.

3 De maneira muito geral e sucinta, é possível afirmar que as abordagens que tomam a criança como produtora de cultura concebem a infância como um universo próprio de significação do mundo e da sociedade, sendo-o de modo completamente distinto do universo cultural do adulto. Mesmo submetidas a uma sociedade de massas, tal como os adultos, as crianças possuiriam um olhar interpretativo e diferentes linguagens por meio dos quais elas conceberiam o mundo ao seu redor. A infância é pensada, portanto, a partir de um pressuposto de especificidade radical: apesar de ser uma categoria geracional que se delineia em relação à categoria de adulto e às demais categorias sociais (o que faz com que ela não seja tomada como categoria universal, mas como uma categoria plural, que dialoga com os diferentes contextos histórico-culturais), a infância seria dotada de valor em si mesma. Isto assim o é, pois, de acordo com tal perspectiva, ela possui os seus próprios instrumentos culturais e cognitivos para pensar o mundo e interferir na sociedade, não tendo sua relevância justificada unicamente em contraposição ao mundo adulto.

4 É importante ressaltar que essa noção de 'igualização’ consiste em um princípio regulador abstrato e não em uma realidade empírica.

5 Tradução nossa: ‘[...] marca la preocupación y muchas veces la desorientación por un fenómeno que ocupa un lugar cada vez más importante en los debates sociológicos contemporáneos: los cambios en el estatus de la infancia moderna y las predicciones respecto de su extinción'.

6 Tradução nossa: 'En cierta medida la infancia no desaparece, sino que se convierte en medio para erosionar lo infantil. Dicho con otras palabras, los criterios de demarcación entre infancia y adultez se resquebrajan - lo infantil se desdibuja - y la infancia, por su parte, coloniza y se expande - se resignifica - en los ámbitos de lo social y lo cultural. [...] La cotidianidad se llena de símbolos, en lo que se otorgan características divinas y sagradas a los niños en el sentido de deidades redentoras'.

7 Para nos referir ao movimento de renovação da educação iniciado entre o término do século XIX e meados do século XX, utilizaremos o termo 'pedagogias renovadas'. Não empregamos este termo, no entanto, como sinônimo de Escola Nova, pois, tal designação abarca um conjunto de autores e teorias que extrapolam os limites do movimento escola-novista. Trata-se de correntes plurais que, de alguma maneira, propuseram transformações nos princípios e no modelo escolar e pedagógico consagrado na tradição educacional. 
Representações da Infância nos Discursos Pedagógicos

8 Tradução nossa: 'Si l'enfant vaut, c'est qu'il n'est pas encore déformé par une societé pervertie. Il porte donc en lui les gages d'une société meilleure. La plupart des sectateurs de l'éducation nouvelle transfèrent au niveau de l'acte pédagogique leur refus de la société établie et leur espoir de fonder un ordre social nouveau. [...] Le changement est à chercher dans l'homme, et l'enfant, dans sa pureté et sa naïveté première, porte les promesses et la possibilité d'un ordre nouveau. La révolution véritable est pour eux une révolution pacifique que l'action pédagogique prépare. L'enfant est l'être de demain, disponible pour tous les progrès, porteur naturel des espoirs d'une société nouvelle'.

\section{Referências}

AGAMBEN, Giorgio. Infância e História: destruição da experiência e origem da história. Belo Horizonte: Editora UFMG, 2008.

ARCE, Alessandra. Pedagogia da Infância ou Fetichismo da Infância? In: DUARTE, Newton. Crítica ao Fetichismo da Individualidade. Campinas: Autores Associados, 2012. P. 129-150.

ARENDT, Hannah. Entre o Passado e o Futuro. São Paulo: Perspectiva, 2003. ARIÈS, Philippe. História Social da Criança e da Família. Rio de Janeiro: LTC, 1981. CALDAS AULETE, Dicionário. Verbete: Representação. Aulete Digital, Rio de Janeiro: Lexikon, 2015. Disponível em: <http://www.aulete.com.br/ representa\%C3\%A7\%C3\%A3o>. Acesso em: 01 abr. 2015.

CAMBI, Franco. A História da Pedagogia. São Paulo: Fundação Editora da UNESP, 1999.

DEWEY, John. Experiência e Educação. São Paulo: Companhia Editora Nacional, 1976.

DUARTE, Newton. O Bezerro de Ouro, o Fetichismo da Mercadoria e o Fetichismo da Individualidade. In: DUARTE, Newton (Org.). Crítica ao Fetichismo da Individualidade. Campinas: Autores Associados, 2012. P. 1-17.

GAGNEBIN, Jeanne Marie. Sete Aulas sobre Linguagem, Memória e História Rio de Janeiro: Imago, 2005.

HARTOG, François. Regimes de Historicidade: presentismo e experiências do tempo. Belo Horizonte: Autêntica Editora, 2013.

HERBART, Johan Friedrich. Pedagogia Geral. Lisboa: Fundação Calouste Gulbekian, 2014.

KANT, Immanuel. Sobre a Pedagogia. Piracicaba: Editora UNIMEP, 2011.

KOSELLECK, Reinhart. Futuro Passado: contribuição à semântica dos tempos históricos. Rio de Janeiro: Contraponto; Editora PUC-Rio, 2006.

LEGRAND, Louis. L’Éducation Nouvelle et ses Ambiguïtés. Revue Française de Pédagogie, Lyon, v. 11, n. 1, p. 5-11, abr./jun. 1970. Disponível em: <http:// www.persee.fr/web/revues/home/prescript/article/rfp_05567807_1970_ num_11_1_1784>. Acesso em: 02 abr. de 2015.

NARODOWSKI, Mariano. Infância e Poder: conformação da pedagogia moderna. Bragança Paulista: Editora da Universidade São Francisco, 2001.

NARODOWSKI, Mariano. No es Fácil ser Adulto. Asimetrías y equivalencias en las nuevas infancias y adolescencias. Educación y Pedagogía, Medellín, v. 23, n. 60, p. 101-114, maio/ago. 2011. Disponível em: <http://aprendeenlinea.udea.edu.co/revistas/index.php/revistaeyp/article/viewFile/11418/10436>. Acesso em: 30 mar. 2015.

320 Educação \& Realidade, Porto Alegre, v. 42, n. 1, p. 299-321, jan./mar. 2017. 
NEIL, Alexander Sutherland. Liberdade sem Medo. São Paulo: IBRASA, 1973.

PEÑA, Andrés Klaus Runge. Heterotopías para la Infancia: reflexiones a propósito de su 'desaparición' y del 'final de su educación'. Revista Latinoamericana de Ciencias Sociales, Niñez y Juventud, Manizales, v. 6, n. 1, p. 31-53, jan./jun. 2008. Disponível em: <http://revistaumanizales.cinde.org.co/index.php/Revista-Latinoamericana/article/view/264/132>. Acesso em: 01 abr. 2015.

POSTMAN, Neil. O Desaparecimento da Infância. Rio de Janeiro: Graphia, 1999.

RENAUT, Alain. A Libertação das Crianças: a era da criança cidadã - contribuição filosófica para uma história da infância. Lisboa: Instituto Piaget, 2002.

SARMENTO, Manuel Jacinto. Sociologia da Infância: correntes e confluências. In: SARMENTO, Manuel; GOUVEA, Maria Cristina Soares de (Org.). Estudos da Infância: educação e práticas sociais. Petrópolis: Vozes, 2008.

SILVA, Franklin Leopoldo e. Descontrole do Tempo Histórico e Banalização da Experiência. In: NOVAES, Adauto (Org.). Mutações: ensaios sobre as novas configurações do mundo. Rio de Janeiro: Agir; São Paulo: Edições SESC SP, 2008. P. 149-162.

SNYDERS, George. Pedagogia Progressista. Coimbra: Livraria Almedina, 1974.

TRISCIUZZI, Leonardo; CAMBI, Franco. La Infancia en la Sociedad Moderna: del descubrimiento a la desaparición. Documento de Trabajo. Roma: Riuniti, 1993. Disponível em: <http://www.inau.gub.uy/biblioteca/Trisciuzzi.pdf>. Acesso em: 23 mar. 2015.

Crislei de Oliveira Custódio é doutoranda em Educação, mestre e licenciada em Pedagogia pela Faculdade de Educação da Universidade de São Paulo. É bolsista CAPES e membro integrante do Grupo de Estudos sobre Educação e o Pensamento Contemporâneo, ligado ao departamento de Filosofia e Ciências da Educação da FE-USP.

E-mail: crislei.paula@usp.br 